\title{
Metabolically inactive insulin analogue does not prevent autoimmune diabetes in NOD mice
}

\author{
Juha Grönholm ${ }^{1}$ • Philippe P. Pagni ${ }^{2,3}$ • Minh N. Pham ${ }^{2}$ - Claire B. Gibson ${ }^{2}$ • \\ Paul F. Macomber ${ }^{4}$. José Luis Vela ${ }^{2}$ - Matthias von Herrath ${ }^{2} \cdot$ Michael J. Lenardo $^{1}$
}

Received: 4 November 2016 / Accepted: 20 March 2017 / Published online: 28 April 2017

(C) Springer-Verlag (outside the USA) 2017

\begin{abstract}
Aims/hypothesis Insulin is widely considered to be a driver antigen in type 1 diabetes in humans and in mouse models of the disease. Therefore, insulin or insulin analogues are candidates for tolerogenic drugs to prevent disease onset in individuals with risk of diabetes. Previous experiments have shown that autoimmune diabetes can be prevented in NOD mice by repeated doses of insulin administered via an oral, nasal or parenteral route, but clinical trials in humans have not succeeded. The hypoglycaemic activity of insulin is dose-limiting in clinical studies attempting tolerance and disease prevention. Here, we aimed to investigate the therapeutic potential of metabolically inactive insulin analogue (MII) in NOD mice.

Methods The tolerogenic potential of MII to prevent autoimmune diabetes was studied by administering multiple i.v. or s.c. injections of MII to non-diabetic 7-12-week-old
\end{abstract}

Electronic supplementary material The online version of this article (doi:10.1007/s00125-017-4276-5) contains peer-reviewed but unedited supplementary material, which is available to authorised users.

Michael J. Lenardo

lenardo@nih.gov

1 Molecular Development of the Immune System Section, Laboratory of Immunology, National Institute of Allergy and Infectious Diseases (NIAID) and Clinical Genomics Program, NIAID, National Institutes of Health, Building 10, Room 11D14, 10 Center Drive,

Bethesda, MD 20814, USA

2 Novo Nordisk Type 1 Diabetes Center, Novo Nordisk Research Center, Seattle, WA, USA

3 La Jolla Institute for Allergy and Immunology, La Jolla, CA, USA

4 Wellstat Diagnostics, Gaithersburg, MD, USA female NOD mice in three geographical colony locations. The incidence of diabetes was assessed from daily or weekly blood glucose measurements. The effect of MII on insulin autoantibody levels was studied using an electrochemiluminescence-based insulin autoantibody assay. The effect on the number of insulin-reactive $\mathrm{CD}^{+}$and $\mathrm{CD}^{+} \mathrm{T}$ lymphocytes in peripheral lymphoid tissue was studied with MHC class I and MHC class II tetramers, respectively.

Results We found that twice-weekly s.c. administration of MII accelerates rather than prevents diabetes. High-dose i.v. treatment did not prevent disease or affect insulin autoantibody levels, but it increased the amount of insulin-reactive $\mathrm{CD}^{+} \mathrm{T}$ lymphocytes in peripheral lymphoid tissue.

Conclusions/interpretation Our data suggest that parenteral MII, even when used in high doses, has little or no therapeutic potential in NOD mice and may exacerbate disease.

Keywords Autoimmune diabetes $\cdot$ Insulin $\cdot$ Non-obese diabetic mouse · Tolerance

$\begin{array}{ll}\text { Abbreviations } \\ \text { APC } & \text { Antigen presenting cell } \\ \text { ECL } & \text { Electrochemiluminescence } \\ \text { HEL } & \text { Hen egg lysozyme } \\ \text { IGRP } & \begin{array}{l}\text { Islet-specific glucose-6-phosphatase catalytic } \\ \text { subunit-related protein }\end{array} \\ \text { MII } & \text { Metabolically inactive insulin analogue } \\ \text { NNRC } & \text { Novo Nordisk Research Center } \\ \text { PD-L1 } & \text { Programmed death-ligand 1 } \\ \text { RICD } & \text { Re-stimulation-induced cell death }\end{array}$




\section{Introduction}

Type 1 diabetes is an autoimmune disease that causes selective pancreatic beta cell demise, leading to insulin deficiency [1]. The NOD mouse develops spontaneous diabetes with similarities to human type 1 diabetes $[2,3]$. Several treatments can prevent or delay diabetes onset in NOD mice, but these have failed in human clinical trials [4]. In NOD mice, insulin is thought to be the driver autoantigen, although other autoantigens, including islet-specific glucose-6-phosphatase catalytic subunit-related protein (IGRP), have been identified [5, 6]. Also, more than half of individuals with type 1 diabetes develop autoantibodies against insulin [7,8]. Thus, insulin is an attractive candidate for disease-prevention studies [4]. Most attempts to antigen-specifically suppress immune responses involve repeated high-dose exposure to the target antigen. Daily parenteral administration of insulin or metabolically inactive insulin analogue (MII) prevents insulitis and diabetes in NOD mice [9-11]. Vaccination with a strong agonist insulin peptide mimetope (insulin B chain core epitope 12-23, in which arginine 22 is substituted with glutamic acid, named mimetope 3 ) has been shown to prevent diabetes and insulitis by converting naive $\mathrm{CD}^{+} \mathrm{T}$ cells to FoxP3-positive $\mathrm{T}$ regulatory cells in NOD mice [12]. Nasal and oral administration of insulin also reduces diabetes in NOD mice $[13,14]$. Unfortunately, repeat studies have failed to confirm the efficacy of oral insulin [15]. Geographical location, microbial flora and facility sterility affect diabetes incidence in NOD mice and may influence treatment outcomes [2, 4].

T cell number during clonal expansion is regulated through re-stimulation-induced cell death (RICD), caused by large antigen doses [16]. Eliminating antigen-specific $\mathrm{T}$ cell clones by RICD is an exciting strategy for tolerance induction and can prevent or treat experimental autoimmune diseases $[17,18]$. Parenteral insulin administration in individuals with risk of type 1 diabetes has not prevented disease, perhaps because the risk of hypoglycaemia limits the dose of insulin administered [4, 19, 20]. Removing the endocrinological activity but retaining antigenic epitopes in insulin may solve this problem. High parenteral doses of an MII might eliminate insulin-reactive $\mathrm{T}$ cells by inducing RICD. We aimed to investigate the tolerogenic potential in NOD mice of a human insulin analogue in which phenylalanine at position B25 has been substituted with aspartic acid (electronic supplementary material [ESM] Fig. 1) [11, 21]. This analogue has $0.014 \%$ insulin receptor binding affinity and minimal hypoglycaemic effect, and is therefore suitable for high-dose parenteral administration [21, 22]. The onset of spontaneous diabetes in NOD mice is variable and can be accelerated by administering parenteral anti-programmed death-ligand 1 (PD-L1) [23]. Here, we have studied the potential of parenterally administered MII to prevent both spontaneousonset and anti-PD-L1-induced diabetes in NOD mice.

\section{Methods}

Experimental animals Female NOD/ShiLtJ mice, 4-12 weeks old, were purchased from Jackson Laboratories (Bar Harbor, ME, USA or Sacramento, CA, USA) and acclimatised in-house prior to each experiment. NOD-CD2-GFP transgenic mice (provided by A. Cooke, Cambridge, UK) were bred at the National Institute of Allergy and Infectious Diseases (NIAID; Bethesda, MD, USA). Mice were housed in sterilised cages with free access to water and standard mouse chow (irradiated Purina Lab Diet 5053 at Seattle and La Jolla, autoclaved Envigo lab diet 7017 at NIAID) in room with a $12 \mathrm{~h}$ day/night cycle. Age-matched female mice were used in all in vivo experiments. Mouse experiments were performed with the approval of the respective institutional animal care and use committees (La Jolla Institute for Allergy and Immunology, Novo Nordisk Research Center [NNRC] Seattle and NIAID Bethesda). $2 \mu \mathrm{g}, 20 \mu \mathrm{g}$ and $200 \mu \mathrm{g}$ s.c. doses or a ramp up from $2 \mu \mathrm{g}$ to $200 \mu \mathrm{g}$, twice weekly for 5 weeks s.c. MII doses were studied at La Jolla Institute for Allergy and Immunology. Doses of $200 \mu \mathrm{g}$ and $500 \mu \mathrm{g}$ s.c. and ramp up from $200 \mu \mathrm{g}$ to $500 \mu \mathrm{g}$ of MII and MII combination with protamine $(2 \mu \mathrm{g}, 20 \mu \mathrm{g}$ and $200 \mu \mathrm{g}$ of MII) twice weekly for 5 weeks were performed in NNRC, Seattle. Daily $5 \mu$ g s.c. dosing and all the i.v. dosing experiments ( $400 \mu \mathrm{g}$ of MII) were studied at NIAID, Bethesda.

Administration of MII MII was provided by Novo Nordisk (Måløv, Denmark) and was prepared fresh weekly, sterile filtered and stored at $4{ }^{\circ} \mathrm{C}$. MII and protamine sulphate were mixed 1:1 in PBS. Injections, $200 \mu$ l, were performed s.c. in the back, or i.v. retro-orbitally or into the lateral tail vein. Twice-daily doses were administered at 08:00 $\mathrm{h}$ and 18:00 $\mathrm{h}$ every other day. Intravenously administered ovalbumin (OVA; EndoFit Ovalbumin, InvivoGen, San Diego, CA, USA) was used as a negative control protein in part of the experiments.

Administration of mimetope 3 Osmotic pumps (Alzet, model 1002, Cupertino, CA, USA) were primed overnight with $100 \mu \mathrm{l}$ sterile PBS or mimetope 3 (modified insulin B chain core epitope 12-23: VEALYLVCGEEG) and implanted s.c. in isoflurane-anaesthetised 9-week-old female NOD mice through a small mid-scapular transverse incision. The wound was closed with surgical glue and/or wound clips or was sutured. Mice were monitored at least twice daily during the first week following surgery. The osmotic pump delivered $5 \mu \mathrm{g}$ mimotope 3 per day, with release rate $0.25 \mu \mathrm{l} / \mathrm{h}$. 
Carprofen, 5-10 mg/kg administered s.c., was used for pain relief during the recovery period. Pumps were removed after 14 days. Mice with blood glucose $>13.9 \mathrm{mmol} / 1$ were excluded from the experiment.

Diabetes assessment in NOD mice Diabetes incidence was monitored weekly using the OneTouch UltraMini (LifeScan, Milpitas, CA, USA) or the Bayer Contour USB (Whippany, NJ, USA) glucose meter. Non-fasting blood glucose $\geq 13.9 \mathrm{mmol} / 1$ for two consecutive measurements was considered to indicate diabetes.

Anti-PD-L1 acceleration of diabetes Diabetes onset in 7week-old NOD mice was accelerated with three i.v. doses $(200 \mu \mathrm{l})$ of in vivo grade anti-PD-L1 (BioXcell, West Lebanon, NH, USA) $(500 \mu \mathrm{g}$ on the first day and $250 \mu \mathrm{g}$ on days 3 and 5). Rat IgG2b (BioXcell, West Lebanon, NH, USA) was the negative control. Antibody was diluted in sterile PBS.

In vitro RICD assay $\mathrm{I} .85$ hybridoma cells (provided by E. Unanue, Washington University, St Louis, MO, USA) have been described previously [24]. Splenocytes from non-diabetic CD2-GFP-NOD males were irradiated $30 \mathrm{~Gy}$ and pulsed with antigen for $3 \mathrm{~h}$ at $37^{\circ} \mathrm{C}$. Hybridoma cells, $5 \times 10^{4}$, were mixed with antigen-pulsed splenocytes, $5 \times 10^{5}$, and cultured at $37^{\circ} \mathrm{C}$ for $72 \mathrm{~h}$. Dead cells were labelled with $50 \mathrm{nmol} / 1$ TO-PRO-3 (Life Technologies, Carlsbad, CA, USA) and analysed with FACSCalibur (BD, Franklin Lakes, NJ, USA). Cell loss was quantified as percentage cell loss $=[1-($ number of viable cells [treated $] /$ number of viable cells [untreated])] $\times 100$. Plate-bound anti-CD3 (clone 2C11) was the positive control. $\mathrm{HEL}_{11-25}$ and InsB $_{9-23}$ peptides were obtained from the NIAID core (Research Technology Branch, Protein Chemistry Section, Bethesda, MD, USA).

Cell isolation and flow cytometry Mice were anaesthetised with $100 \mathrm{mg} / \mathrm{kg}$ ketamine (Putney, Portland, ME, USA) and $15 \mathrm{mg} / \mathrm{kg}$ xylazine (AnaSed, Akom, Decatur, IL, USA), i.p., and perfused with PBS $+0.5 \mu \mathrm{mol} / \mathrm{l}$ EDTA. Pancreases were inflated through the common bile duct with digestion buffer $(1 \mathrm{mg} / \mathrm{ml}$ collagenase $1 \mathrm{~A}$ and $50 \mu \mathrm{g} / \mathrm{ml}$ DNAse1 (both from Sigma, Saint Louis, MO, USA) in Hanks' Balanced Salt Solution (HBSS) with $\mathrm{Mg}^{2+}$ and $\mathrm{Ca}^{2+}$ ), and digested for $15 \mathrm{~min}$ at $37^{\circ} \mathrm{C}$. Cells were stained with $0.02 \mathrm{mg} / \mathrm{ml}$ class II tetramer for either insB $\mathrm{B}_{10-23 \mathrm{r} 3}$ or $\mathrm{HEL}$ for $2 \mathrm{~h}$ at $37^{\circ} \mathrm{C}$, followed by staining with fluorescent-labelled antibodies for $1 \mathrm{~h}$ at room temperature. Flow cytometry was conducted with LSR II (BD, Franklin Lakes, NJ, USA). Class I tetramer staining for listeriolysin $\left(\mathrm{LLO}: \mathrm{H}-2 \mathrm{~K}^{\mathrm{d}}\right)$, insulin $\left(\mathrm{InsB}_{15-23}: \mathrm{H}-2 \mathrm{~K}^{\mathrm{d}}\right)$ or NRP-V7 (NRP-V7:H-2K $\left.\mathrm{K}^{\mathrm{d}}\right)$ was performed with samples on ice for $1 \mathrm{~h}$. Tetramers were obtained from the National Institutes of Health (NIH) tetramer core (Emory University, Atlanta, GA, USA).

Murine insulin autoantibody electrochemiluminescence assay The insulin autoantibody electrochemiluminescence (ECL) assay was performed on serum using an M-SERIES M1MR analyser (BioVeris, Gaithersburg, MD, USA) as described previously [25]. Recombinant human insulin produced in Escherichia coli (MBL International Corporation, Woburn, MA, USA) was biotinylated using EZ-Link Sulfo-NHS-Biotin (Thermo Scientific, Rockford, IL, USA) and coated onto Dynabeads M-280 Streptavidin (Invitrogen, Oslo, Norway).

Statistical analysis Statistical analyses and power calculations were carried out using Prism v6 and StatMate v1 software (GraphPad, La Jolla, CA, USA). A $p$ value $\leq 0.05$ was considered statistically significant. A Mantel-Cox logrank test was used to estimate statistical significance of survival. An unpaired Student's $t$ test was used for flow cytometry data.

\section{Results}

Subcutaneous administration of MII does not prevent diabetes in NOD mice In order to study the tolerogenic potential of MII, non-diabetic 8-week-old female NOD mice were treated with either vehicle or MII at constant $2 \mu \mathrm{g}, 20 \mu \mathrm{g}$ and $200 \mu \mathrm{g}$ s.c. doses or a ramp up from $2 \mu \mathrm{g}$ to $200 \mu \mathrm{g}$, twice weekly for 5 weeks. We observed no prevention or delay of disease onset, but rather an increase in disease incidence with $20 \mu \mathrm{g}$ and $200 \mu \mathrm{g}$ doses compared with PBS-treated controls (Fig. 1a). Animals treated with MII also started to become diabetic earlier when compared with PBS-treated animals (5/7 mice in $200 \mu \mathrm{g}$ MII and 3/7 mice in both $20 \mu \mathrm{g}$ and MII ramp up groups, compared with 0/7 in PBS group, became diabetic by the age of 16 weeks), indicating that MII may accelerate the disease. As diabetes incidence differs in NOD colonies, we treated 9-week-old NOD mice housed in a different location (NNRC, Seattle) with higher MII doses ( $200 \mu \mathrm{g}, 500 \mu \mathrm{g}$ or ramp up from $200 \mu \mathrm{g}$ to $500 \mu \mathrm{g}$ ), but again were unable to prevent diabetes (Fig. 1b). We further analysed the combined results from these two experiments by comparing the diabetes incidence in MII-treated mice with that in the combined group of vehicle (PBS)-treated mice and with the historical diabetes incidence in untreated NOD mice in our colony (La Jolla, 2012). Both the $20 \mu \mathrm{g}$ and $200 \mu \mathrm{g}$ doses of MII accelerated the disease compared with our concurrent vehicle-treated controls, but there was no significant difference from historical diabetes incidence in untreated animals (ESM Fig. 2). Taken together, we saw no 

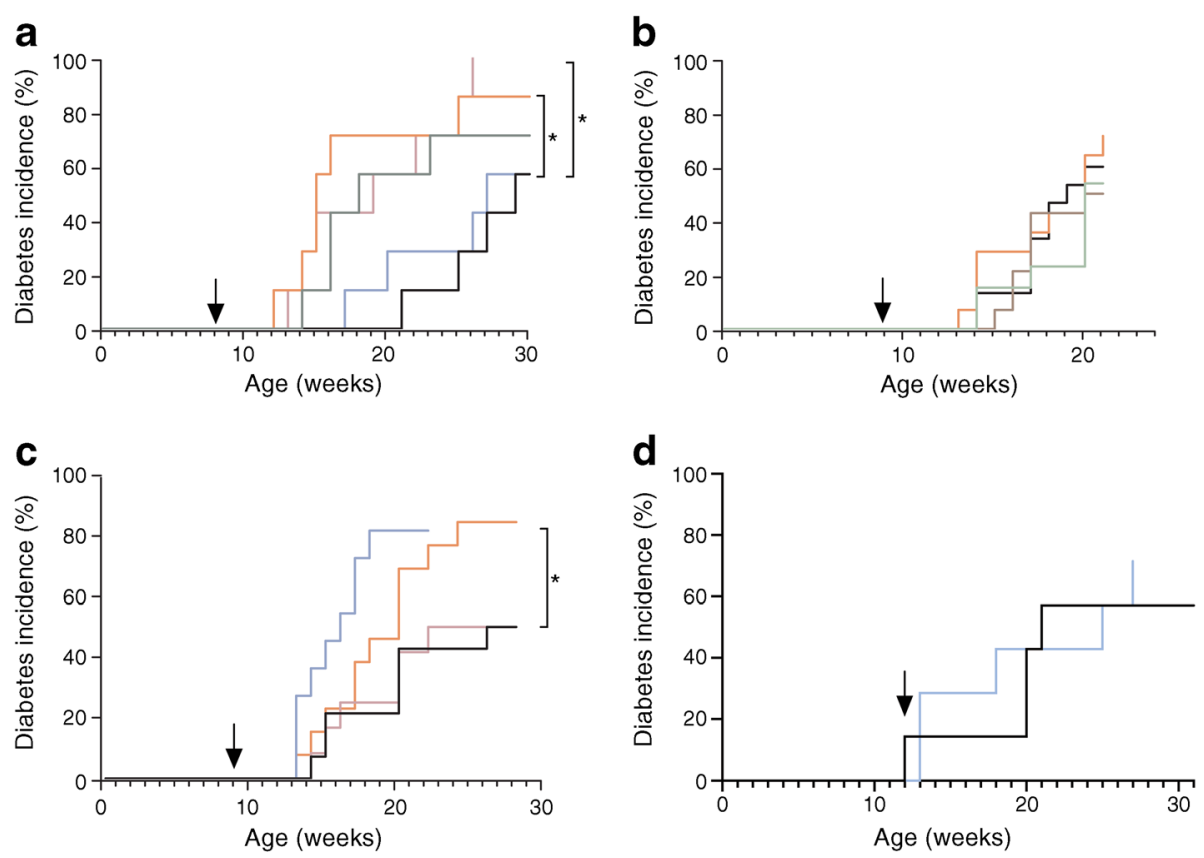

Fig. 1 Subcutaneous administration of MII does not prevent diabetes onset in NOD mice. (a) Diabetes incidence in NOD mice treated twice weekly with s.c. PBS or MII from 8 weeks of age for a period of 5 weeks (La Jolla Institute for Allergy and Immunology). Black, PBS; light blue, $2 \mu \mathrm{g}$ MII; pink, $20 \mu \mathrm{g}$ MII; orange, $200 \mu \mathrm{g}$ MII; dark green, ramp up from 2 to $200 \mu \mathrm{g}$ MII ( $n=7$ in all groups). Hypothesising a $20 \%$ baseline proportion of non-diabetic animals in the PBS control group, we determined that our experiment had $80 \%$ power to detect an effect size of $59.1 \%$ with a significance level $(\alpha)$ of 0.05 (two-tailed) with a total sample size of 14 (7 vs 7). (b) Diabetes incidence for NOD mice treated twice weekly with s.c. PBS or MII at 9 weeks of age for a period of 5 weeks (NNRC, Seattle). Black, PBS $(n=15)$; orange, $200 \mu \mathrm{g}$ MII

indication of tolerance induction with twice-weekly s.c. administration of MII.

Protamine is a polypeptide that prolongs insulin action. However, combining protamine with MII did not prevent diabetes (Fig. 1c). In fact, $2 \mu \mathrm{g}$ MII with protamine exacerbated the disease before 28 weeks of age. As twice-weekly administration was not effective, we next tested daily administration of $5 \mu \mathrm{g}$ MII, but this did not prevent disease in our colony at NIAID, Bethesda (Fig. 1d). Of note, two of seven mice receiving daily MII died without diabetes before 31 weeks of age, possibly because of hypoglycaemia.

As we failed to induce tolerance with s.c. MII, we tested an insulin peptide, mimetope 3 , administered s.c. via an osmotic pump. Surprisingly, we did not detect any tolerogenic potential with mimetope 3 (ESM Fig. 3), which has previously shown efficacy [12]. Instead, all the animals that received mimetope 3 became diabetic. Of note, mimetope 3 was detectable by mass spectrometry in serum 1 week after pump implantation, indicating that the pump worked (data not shown).

MII can induce RICD of insulin-reactive $T$ cell hybridomas in vitro We tested the tolerogenic potential of MII using

( $n=14)$; brown, $500 \mu \mathrm{g}$ MII $(n=15)$; light green, ramp up from 200 to $500 \mu \mathrm{g}$ MII $(n=13)$. (c) 9-week-old NOD mice were treated with varying amounts of MII with protamine twice weekly for 5 weeks (NNRC, Seattle). Black, PBS $(n=14)$; light blue, $2 \mu \mathrm{g}$ MII + protamine $(n=11)$; purple, $20 \mu \mathrm{g}$ MII + protamine $(n=13)$; orange, $200 \mu \mathrm{g}$ MII + protamine $(n=13)$. (d) Diabetes incidence for daily s.c. administration of MII, started at the age of 12 weeks (NIAID, Bethesda). Black, PBS ( $n=7)$; light blue, $5 \mu \mathrm{g}$ MII $(n=7)$. The arrows indicate treatment onset. Blood glucose values were measured weekly to 30 weeks (a), 22 weeks (b), 28 weeks (c) or 31 weeks of age (d). Diabetes was defined as blood glucose $\geq 13.9 \mathrm{mmol} / 1$ in two consecutive measurements. ${ }^{*} p \leq 0.05$ (Mantel-Cox logrank test)

an in vitro RICD assay with insulin $\mathrm{B}_{9-23}$-epitope-reactive monoclonal mouse $\mathrm{CD} 4^{+}$hybridoma cell line I.85. As a positive control, plate-bound anti-CD3 induced dose-dependent death of the I.85 cells (Fig. 2a). We used splenocytes from non-diabetic CD2-GFP-NOD mice as antigen presenting cells (APCs) and compared the effect of MII on cell death with that of control peptide from hen egg lysozyme (HEL), or human insulin $\mathrm{B}_{9-23}$-peptide. We saw significant cell death with $100 \mu \mathrm{mol} / \mathrm{l}$ and $250 \mu \mathrm{mol} / 1$ $\mathrm{B}_{9-23}$-peptide compared with very little with HEL (Fig. 2b). MII showed significant cell death with all doses (10-250 $\mu \mathrm{mol} / \mathrm{l})$. Of note, sterile-filtered insulin peptide or MII was not toxic to the I.85 cells when incubated without APCs (data not shown). Taken together, this suggests that MII processed by APCs can induce RICD of insulin-reactive T cells.

Intravenous high-dose MII treatment does not prevent or delay diabetes onset in NOD mice To further test tolerance induction with high-dose MII, 7-week-old NOD mice were injected i.v. with either PBS or $400 \mu \mathrm{g}$ MII twice weekly. MII-treated mice developed diabetes slightly earlier 


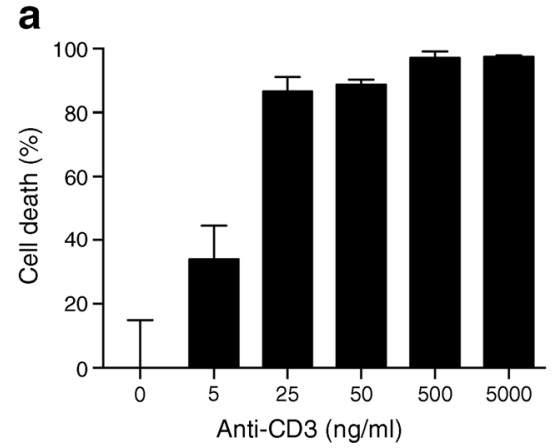

Fig. 2 MII can induce RICD in the insulin $\mathrm{B}_{9-23}$ peptide-reactive hybridoma cell line I.85 in vitro. (a) Positive control in vitro RICD assay with anti-CD3. I.85 hybridoma cells were plated on anti-CD3 coated 96-well plates and analysed for cell death by flow cytometry after $24 \mathrm{~h}$. (b) Irradiated CD2-GFP-NOD mouse splenocytes were pulsed with the concentrations indicated of $\mathrm{HEL}_{11-25}$ peptide, insulin $\mathrm{B}_{9-23}$ peptide or MII for $3 \mathrm{~h}$ before plating together with I. 85 hybridoma cells. Cells were

(Fig. 3a). The mice were euthanised at age 16 weeks (when 6/7 MII-treated and 5/7 PBS-treated mice were diabetic) and $\mathrm{CD}^{+} \mathrm{T}$ cells were stained with MHC class I tetramers for insulin and IGRP (NRP-V7:H-2K ${ }^{\mathrm{d}}$, MHC class I tetramer with IGRP mimetope peptide), both of which are autoantigens in NOD mice. We saw no difference in the number of tetramer-reactive $\mathrm{CD} 8^{+} \mathrm{T}$ cells in the pancreas, pancreatic draining lymph nodes or in the spleen between MII-treated and control mice (Fig. 3b-d).

Next, we administered twice daily, every other day, for a total of six doses, a regimen of i.v. MII in 7-week-old female NOD
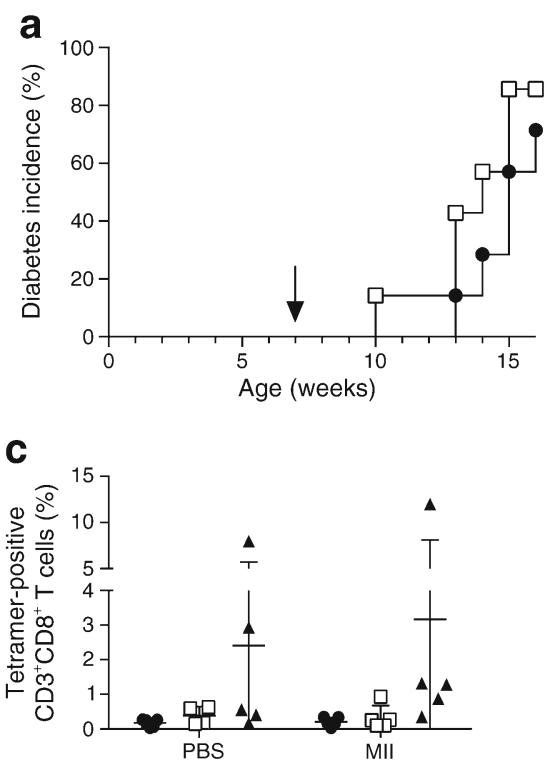

Fig. 3 High-dose i.v. treatment with MII twice weekly for 4 weeks does not prevent diabetes onset in NOD mice. (a) NOD mice were i.v. injected twice weekly with either $200 \mu \mathrm{l}$ PBS or $400 \mu \mathrm{g}$ MII starting at 7 weeks of age for a total of 4 weeks $(n=7)$. Diabetes incidence was monitored by blood glucose measurements twice weekly. Diabetes was defined as blood glucose $\geq 13.9 \mathrm{mmol} / 1$ in two consecutive measurements. The arrow shows treatment onset. Black circles, PBS; white squares, MII. (b-d) Class 1

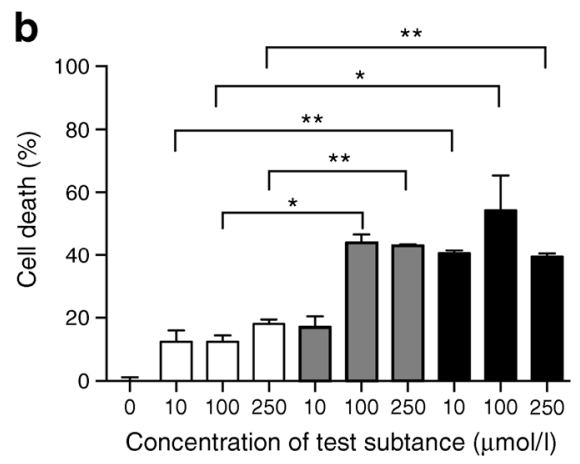

incubated for $70 \mathrm{~h}$ before analysis of cell death by flow cytometry. White, $\mathrm{HEL}_{11-25}$; grey, insulin $\mathrm{B}_{9-23}$; black, MII. Dead cells were labelled with TO-PRO-3-iodide DNA-binding dye in (a) and (b). Results representative of three independent experiments are shown. Graphs show the mean percentage of cell loss $[1-$ (number of viable cells [treated]/ number of viable cells [untreated])] $\times 100 \pm$ SEM. $* p \leq 0.05, * * p \leq 0.01$

mice, but found that it did not prevent disease (Fig. 4a). As anti-PD-L1 treatment accelerates diabetes onset in NOD mice, we hypothesised that administration of anti-PD-L1 would increase the number of activated insulin autoreactive cells that could be clonally deleted with MII. We found that MII + anti-PD-L1 in 7-week-old NOD mice hastened disease onset before day 10 (Fig. 4b). There was no significant difference in insulin autoantibody levels between mice in different treatment groups in these two experiments (ESM Fig. 4).

As the trend in all our experiments was disease exacerbation with MII, we examined the effect on

b
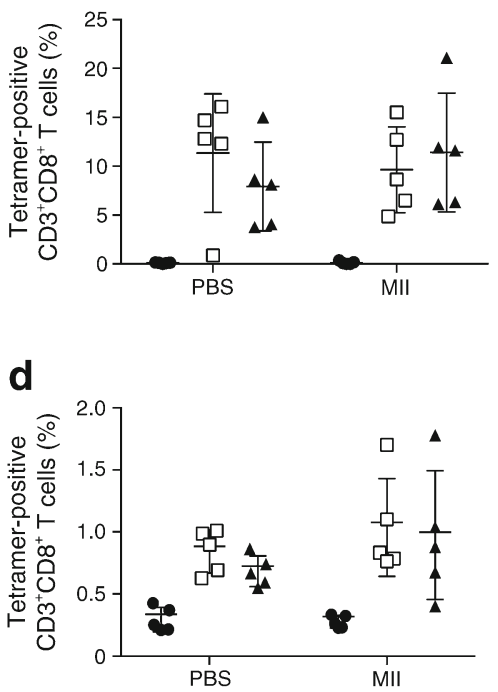

tetramer staining for listeriolysin $\left(\mathrm{LLO}: \mathrm{H}-2 \mathrm{~K}^{\mathrm{d}}\right)$ as a negative control, insulin $\left(\mathrm{InsB}_{15-23}: \mathrm{H}-2 \mathrm{~K}^{\mathrm{d}}\right)$ - or NRP-V7 (NRP-V7:H-2 $\left.\mathrm{K}^{\mathrm{d}}\right)$-specific $\mathrm{CD}^{+}{ }^{\mathrm{T}}$ cells from pancreases (b), pancreatic lymph nodes (c) or spleens (d) of mice from the tolerance experiment described in (a). Organs were harvested from the mice at age 16 weeks (when $~ 80 \%$ of the mice were diabetic in both groups) $(n=5)$. Error bars indicate SD. Black circles, listeriolysin; white squares, insulin; black triangles, NRP-V7 
a

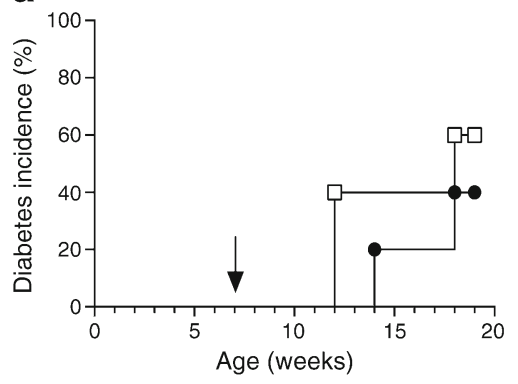

C

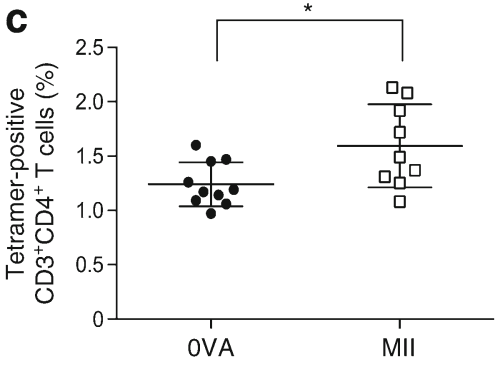

Fig. 4 Repeated high-dose administration of MII tends to accelerate diabetes onset in NOD mice and increases the proportion of insulin-specific $\mathrm{CD}^{+} \mathrm{T}$ cells in the peripheral lymphoid tissue. (a) CD2-GFP-NOD mice, 7 weeks old, were treated with either $400 \mu \mathrm{g}$ OVA or MII twice daily, every other day, for a total of six i.v. injections. The arrow indicates treatment onset. Black circles, OVA; white squares, MII. (b) Diabetes onset in CD2-GFP-NOD mice was induced with three i.v. injections of anti-PD-L1 (on days 0,2 and 4) followed by insulin analogue or OVA control protein i.v. for a total of six doses (on days 3, 5 and 7). Rat $\mathrm{IgG} 2 \mathrm{~b}$ was used as an isotype control for anti-PD-L1. White squares,

insulin-reactive $\mathrm{CD}^{+} \mathrm{T}$ cells of i.v. MII administered twice daily, every other day, for a total of six doses, starting at 7 weeks of age. MII treatment significantly increased the total number of insulin $\mathrm{B}_{10-23 r}$ : $:-\mathrm{A}^{\mathrm{g} 7}$ MHC-II-tetramer-reactive $\mathrm{CD}^{+} \mathrm{T}$ cells in pooled spleen and mesenteric lymph nodes on day 6 (Fig. 4c). We also observed a trend towards increased numbers of activated insulin-reactive $\mathrm{CD} 4^{+} \mathrm{CD} 44^{+} \mathrm{T}$ cells in peripheral lymphoid tissue (Fig. 4d). Thus, i.v. treatment with $\mathrm{MII}$ appeared to induce reactive $\mathrm{CD} 4^{+} \mathrm{T}$ cells that may worsen diabetes in NOD mice.

\section{Discussion}

Insulin is believed to be the driver antigen for diabetogenesis in the NOD mouse [5]. We wanted to test the tolerogenic potential of MII administered via s.c. and i.v. routes to NOD mice. We failed to induce tolerance in our experiments, a finding that differs from previously published results [11]. Instead, we observed acceleration of disease with higher s.c. doses of MII when compared with vehicle-administered controls in our first experiment conducted in La Jolla (Fig. 1a).

The location of NOD colonies affects diabetes incidence, and may also alter the therapeutic effectiveness of the antigen therapy $[2,4]$. Recently, the effect of anti-CD3 therapy on b

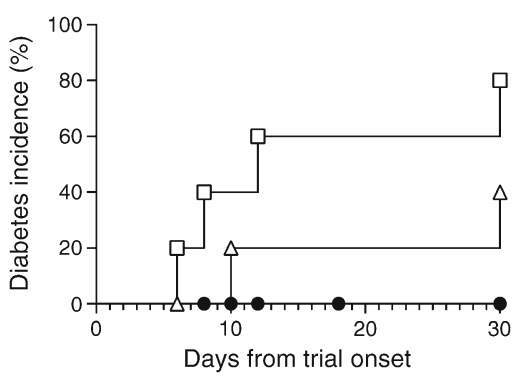

d

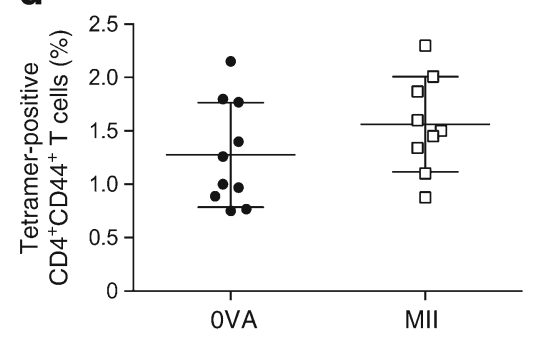

insulin analogue; white triangles, OVA control protein; black circles, rat IgG2b. Diabetes incidence was monitored by blood glucose measurement from the lateral tail vein twice weekly (a) or daily (b). Diabetes was defined as blood glucose $\geq 13.9 \mathrm{mmol} / \mathrm{l}$ in two consecutive measurements. $n=5-6$. (c, d) Percentages of $\mathrm{CD}^{+}{ }^{+} \mathrm{CD} 4^{+} \mathrm{T}$ cells $(\mathbf{c})$ and activated $\mathrm{CD}^{+} \mathrm{CD} 4^{+} \mathrm{CD} 44^{+} \mathrm{T}$ cells $(\mathbf{d})$ reactive with insulin $\mathrm{B}_{10-23 \mathrm{r} 3}: \mathrm{I}_{-} \mathrm{A}^{\mathrm{g} 7}$ tetramer in spleens and mesenteric lymph nodes from CD2-GFP-NOD mice treated with OVA $(n=10)$ or MII $(n=9)$. Data are combined from three independent experiments; error bars indicate SD. $* p \leq 0.05$

reversal of new-onset diabetes in NOD mice was studied simultaneously in four locations. Although anti-CD3 treatment improved diabetes at all sites, there was an unexpected high variability in treatment outcome between study centres [26]. Here, we observed differences in disease acceleration with MII between colony locations (Fig. 1a, b). Furthermore, we were unable to reproduce previously published result with insulin mimetope 3 in NOD mice [12] (ESM Fig. 3). Another recent study was unable to reproduce tolerance with oral insulin in NOD mice [15]. Thus, there are clearly other crucial determinants of disease that can affect the evaluation of immunotherapeutics in NOD mice. However, it is valuable to know if therapies exist that have a robust efficacy at more than one colony location, particularly as insulin is also considered an autoantigen in humans and has been used in clinical trials to prevent type 1 diabetes $[1,4]$.

One amino acid change (alanine to threonine) in position $\mathrm{B} 30$ in insulin abolishes the oral tolerance effect in NOD mice [22]. This amino acid was removed from the analogue used in our study, but was intact in one used in an earlier study by Karounos et al [11]. Using the same dosing approach, we did not observe a difference in diabetes incidence between MII- and vehicle-treated groups (Fig. 1d). Another difference between these trials was the diluent used; we used PBS while 
Karounos et al used $m$-cresol, phenol, glycerol and sodium phosphate diluted in water. Further investigations will be needed to determine if the diluent could affect the therapeutic efficacy of MII.

Mouse autoimmune encephalomyelitis can be ameliorated with repeated i.v. doses of antigen, $400 \mu \mathrm{g}$ twice daily, every other day for a total of six doses, but MII administered with this dosing regimen did not prevent diabetes [17]. We observed that repeated i.v. dosing of MII expanded the number of insulin-reactive $\mathrm{CD}^{+} \mathrm{T}$ cells in the peripheral lymphoid organs, and thus it functioned as an immunogen (Fig. 4c, d). Paradoxically, in vitro, MII can induce apoptosis of an insulin-reactive hybridoma clone (Fig. 2b). In the future, it will be important to test the death-inducing ability of MII with insulin-reactive peripheral $\mathrm{T}$ cells. Notably, $\mathrm{I}-\mathrm{A}^{\mathrm{g} 7} \mathrm{MHC}$ in NOD mice is expected to bind MII peptides very weakly and possibly in different binding registers [3]. Furthermore, NOD mice have two types of insulin-reactive $T$ cells that recognise insulin peptides in different binding registers [27]. Thus, MII treatment may achieve clonal deletion of strongly responding $T$ cells, but simultaneously activate more weakly responding $\mathrm{T}$ cell clones. Also, we believe that the weak peptide-MHC interaction is the reason why relatively high doses of antigen were needed to induce the in vitro RICD shown in Fig. 2b. Additional amino acid changes or other immunological interventions may be necessary to enhance the tolerogenic potential of MII. Antigen therapy could be more effective with the co-administration of an adjuvant. Further studies with adjuvants will be needed, as some adjuvants such as incomplete and complete Freund's adjuvant are known to affect NOD diabetes directly, but these could not be used in humans $[28,29]$. Further work to identify an appropriate and safe adjuvant for humans that enhances efficacy is needed. Although insulin is thought to be the driver antigen in diabetogenesis in NOD mice, epitope spreading also occurs, and $\mathrm{T}$ cells specific for other antigens, such as IGRP, are partly responsible for disease progression. Thus, it may be that our treatment regimen was initiated too late, when epitope spreading had already occurred.

In conclusion, we failed to induce in vivo tolerance with parenteral administration of an MII in three different NOD colonies (La Jolla, NNRC Seattle and NIH Bethesda), indicating that MII alone, even at high doses, is not sufficient to prevent diabetes.

Acknowledgements We thank L. Zheng and K. Shafer-Weaver (both from Laboratory of Immunology, NIAID, NIH, Bethesda, MD, USA) for their scientific advice and B. Chao (Laboratory of Immunology, NIAID, NIH, Bethesda, MD, USA), A. Bel Hani and Y. Manenkova (La Jolla Institute for Allergy and Immunology, La Jolla, CA, USA) for technical assistance. We thank the NIAID Research Technologies Branch for producing the $\mathrm{HEL}_{11-25}$ and insulin $\mathrm{B}_{9-23}$ peptides and the NIH Tetramer Core Facility at Emory University, Atlanta, GA, USA for the tetramers.
Data availability The datasets generated during and/or analysed during the current study are available from the corresponding author on reasonable request.

Funding This research was supported by the Division of Intramural Research, NIAID, Clinical Center and National Human Genome Research Institute, NIH. JG was supported by a fellowship grant from the Sigrid Juselius Foundation and by a grant from the Emil Aaltonen Foundation. Wellstat Immunotherapeutics supported this research with Cooperative Research and Development Agreement (CRADA) C-087-2006 (2006-0203) and Wellstat Diagnostics with CRADA C-022-2006 (2006-0369). The study was also funded in part by Novo Nordisk.

Duality of interest MvH, JLV, PPP, CBG and MNP are employed or affiliated with Novo Nordisk. All other authors declare that there is no duality of interest associated with their contribution to this manuscript.

Contribution statement JG, MvH, JLV, PPP and MJL designed the experiments. JG, JLV, PPP, MNP, PFM and CBG performed the experiments and analysed the results. JG, PPP, MNP, PFM and JLV drafted the manuscript. All authors performed critical analysis of the manuscript and approved the final version to be published. MJL is a guarantor of this study and, as such, had full access to all the data in the study and takes responsibility for the integrity of the data and the accuracy of the data analysis.

\section{References}

1. Atkinson MA, Eisenbarth GS, Michels AW (2014) Type 1 diabetes. Lancet 383:69-82

2. Anderson MS, Bluestone JA (2005) The NOD mouse: a model of immune dysregulation. Annu Rev Immunol 23:447-485

3. Unanue ER (2014) Antigen presentation in the autoimmune diabetes of the NOD mouse. Annu Rev Immunol 32:579-608

4. Reed JC, Herold KC (2015) Thinking bedside at the bench: the NOD mouse model of T1DM. Nat Rev Endocrinol 11:308-314

5. Nakayama M, Abiru N, Moriyama $\mathrm{H}$ et al (2005) Prime role for an insulin epitope in the development of type 1 diabetes in NOD mice. Nature 435:220-223

6. Lieberman SM, Evans AM, Han B et al (2003) Identification of the beta cell antigen targeted by a prevalent population of pathogenic CD8+ T cells in autoimmune diabetes. Proc Natl Acad Sci U S A 100:8384-8388

7. Grönholm J, Lenardo MJ (2015) Novel diagnostic and therapeutic approaches for autoimmune diabetes - a prime time to treat insulitis as a disease. Clin Immunol 156:109-118

8. Yu L, Robles DT, Abiru N et al (2000) Early expression of antiinsulin autoantibodies of humans and the NOD mouse: evidence for early determination of subsequent diabetes. Proc Natl Acad Sci U S A 97:1701-1706

9. Atkinson MA, Maclaren NK, Luchetta R (1990) Insulitis and diabetes in NOD mice reduced by prophylactic insulin therapy. Diabetes 39:933-937

10. Muir A, Peck A, Clare-Salzler M et al (1995) Insulin immunization of nonobese diabetic mice induces a protective insulitis characterized by diminished intraislet interferon-gamma transcription. J Clin Invest 95:628-634

11. Karounos DG, Bryson JS, Cohen DA (1997) Metabolically inactive insulin analog prevents type I diabetes in prediabetic NOD mice. J Clin Invest 100:1344-1348 
12. Daniel C, Weigmann B, Bronson R, von Boehmer H (2011) Prevention of type 1 diabetes in mice by tolerogenic vaccination with a strong agonist insulin mimetope. J Exp Med 208:1501-1510

13. Zhang JZ, Davidson L, Eisenbarth G et al (1994) Suppression of diabetes in nonobese diabetic mice by oral administration of porcine insulin. J Endocrinol Investig 17:573-580

14. Harrison LC, Dempsey-Collier M, Kramer DR, Takahashi K (1996) Aerosol insulin induces regulatory CD8 gamma delta T cells that prevent murine insulin-dependent diabetes. J Exp Med 184:2167-2174

15. Pham MN, Gibson C, Rydén AKE et al (2016) Oral insulin (human, murine, or porcine) does not prevent diabetes in the non-obese diabetic mouse. Clin Immunol 164:28-33

16. Snow AL, Pnadiyan P, Zheng L et al (2010) The power and the promise of restimulation-induced cell death in human immune diseases. Immunol Rev 236:68-82

17. Critchfield JM, Racke MK, Zuniga-Pflucker JC et al (1994) T cell deletion in high antigen dose therapy of autoimmune encephalomyelitis. Science 263:1139-1143

18. Mcfarland HI, Lobito AA, Johnson MM et al (2001) Effective antigen-specific immunotherapy in the marmoset model of multiple sclerosis. J Immunol 166:2116-2121

19. Chaillous L, Lefèvre $H$, Thivolet $C$ et al (2000) Oral insulin administration and residual beta-cell function in recent-onset type 1 diabetes: a multicentre randomised controlled trial. Lancet 356:545549

20. Diabetes Prevention Trial-Type 1 Diabetes Study Group (2002) Effects of insulin in relatives of patients with type 1 diabetes mellitus. N Engl J Med 346:1685-1691
21. Vølund A, Brange J, Drejer K et al (1991) In vitro and in vivo potency of insulin analogues designed for clinical use. Diabet Med 8:839-847

22. Homann D, Dyrberg T, Petersen J et al (1999) Insulin in oral immune "tolerance": a one-amino acid change in the B chain makes the difference. J Immunol 163:1833-1838

23. Ansari MJI, Salama AD, Chitnis T et al (2003) The programmed death-1 (PD-1) pathway regulates autoimmune diabetes in nonobese diabetic (NOD) mice. J Exp Med 198:63-69

24. Levisetti MG, Suri A, Petzold SJ, Unanue ER (2007) The insulinspecific T cells of nonobese diabetic mice recognize a weak MHCbinding segment in more than one form. J Immunol 178:6051-6057

25. Lo B, Swafford ADE, Shafer-Weaver KA et al (2011) Antibodies against insulin measured by electrochemiluminescence predicts insulitis severity and disease onset in non-obese diabetic mice and can distinguish human type 1 diabetes status. J Transl Med 9:203

26. Gill RG, Pagni PP, Kufper T et al (2015) A preclinical consortium approach for assessing the efficacy of combined anti-CD3 plus IL-1 blockade in reversing new-onset autoimmune diabetes in NOD mice. Diabetes 65:1310-1316

27. Mohan JF, Levisetti MG, Calderon B et al (2010) Unique autoreactive $\mathrm{T}$ cells recognize insulin peptides generated within the islets of Langerhans in autoimmune diabetes. Nat Immunol 11:350-354

28. Shoda LD, Young DL, Ramanujan S et al (2005) A comprehensive review of interventions in the NOD mouse and implications for translation. Immunity 2:115-126

29. Liddi R, Beales PE, Rosignoli G, Pozzilli P (2000) Incomplete Freund's adjuvant reduces diabetes in the non-obese diabetic mouse. Horm Metab Res 6:201-206 